\title{
Cosmopolitanism versus Traditionalism and the need to talk about a different divide
}

\section{Eduardo Villanueva- Mansilla}

\author{
Editor in Chief, The Journal of Community \\ Informatics \\ Corresponding Author. \\ evillan@gmail.com
}

2016 has brought many different events, but it is not exactly an audacious idea to state that the world has seen better times than those brought by this year. The fact that Oxford Dictionaries has chosen "post-truth" as the word for this year, show one particular aspect of this troublesome period: reality is becoming a problem.

This Journal has dedicated two of its three issues this year to Data: open data and data literacy. These two related concepts appear as fundamental to deal with a precarious emerging world order: a world awash in bytes, shrunk thanks to the technologies that are at the very base of "community informatics", but that appears to be dealing badly with such an ease of access to information, having fallen for a renewed notion of "community" that denies both difference and a collective perspective on the future. Our world appears to be shrinking in purpose, with many just trying to defend themselves from alleged invasions. The truth is just another victim, and facts are lost in the mayhem.

Communities are now facing a two pronged questioning: from the "cosmopolitan" side, having long benefitted from globalization, where are seen as artifacts of an inglorious past, where a regressive vision of social life combines with many unsatisfied demands, material or otherwise, to take the form of appeals to collective identity and the exigence of respect for traditional understandings of values and beliefs. In such a view, community is seen as a shelter from a new, better world, that requires less certainty and more boldness from individuals; words like "innovation" and "disruption" are used constantly to remind us that the world we live in is not just different but demanding of a different attitude.

Villanueva-Mansilla, E. (2016). Editorial: What is a community, or Cosmopolitanism versus Traditionalism and the need to talk about a different divide. The Journal of Community Informatics, 12(3), 1-3.

Date submitted: 2016-11-28. Date accepted: 2016-11-30.

Copyright (C), 2016 (the authors as stated). Licensed under the Creative Commons AttributionNonCommercial-ShareAlike 2.5. Available at: ci-journal.net. Aquí debería ir el enlace completo. 
From conservative positions, it is precisely that static vision of social life what makes communities a positive factor against the brute forces of modernization by liberal politics. Communities are seen as traditional bulwarks of such understandings of values and beliefs, which are not to be discussed, that should never evolve, but act as guarantees of stability and safety. A retreat to community is the only guarantee that real men and women can withstand the pressures of a liberal order, promoted precisely by those benefitting from globalization and the dissolution of the old order.

Of course, the end result is that the actual interests of different communities are ignored: blaming them or demanding that they act as active resistance to globalization just hide the fact that communities are not static, nor can be defined by conservatism, either as a criticism or as a virtue, but that they are also ignored if not despised by those believing fervently in a new order based on social or economic globalization, on a cosmopolitan outlook that almost by definition is enjoyed by a few, by a minority all around the world.

Also, such an approach denies that communities are suffering from the consequences of both globalization and the resistance to globalization: countries facing obliteration by climate change stand next to communities destroyed either slowly, by homogenizing cultural policies promoted by dominant ethnic or cultural groups, or rapidly, by genocidal warfare promoted by powerful forces of obscurantism.

At the same time, other forms of communal living are being praised. Besides the banal or self serving, like talking about "co-located workspaces" as communities, all the issues around "virtual communities", communities of practice, fan cultures and similar conceptualizations of social interactions through digital media, point towards the fact that individuals, at many different levels of many different societies, have a chance to transform their cultural lives through cultural consumption and interaction. The many examples of transnational families using digital messaging to keep in touch, to coordinate action and ultimately to survive, also show the transformative potential of digital devices and networks to add to life, softening the blow of migration for those that choose to do so, or simply making it possible to find shelter and routes to a final destination, for those forced from their lands through violence and terror.

All this leads to one fundamental question: how to determine exactly what is going on. It is not just the realities on the ground, but especially important is how discursive or symbolic reality, all that is written and disseminated through media for instance, is being constructed. The alarming abandonment of fact in public discourse is only one example of the urgent need to reclaim facts as the only possible basis for establishing policy and for a sensible, cosntructive dialog about society's ailments, at any level. Community is just a word, but it means different things to different people, and of course, it enables different policy approaches and political demands depending on how you decide to understand it and how you use in a political arena. To discern exactly what is being said by someone using exactly the same word becomes a critical issue for our times.

So, there is a new divide, which I will allow myself to call "the reality divide". Do we believe that we can discuss the world, our collective needs and our mutual disagreements, from a consensual, fact-based point of view? Those on the side of a negative answer to this question are to be convinced, or just left outside of the conversation? Can we manage to deal with our 
collective issues, at the community, social and world levels, without agreeing on the same building blocks of reality?

Thus, the need for dealing correctly with data is paramount. At JoCI, we are proud to have added to a potential solution through the publishing of data-oriented issues. My gratitude goes to the guest editors, who did a wonderful job of convening authors and guiding them through the editorial process. Also, of course, to the authors, whose writings will help many to face the complicated nature of open data and data literacy in our changing world. JoCI will strive to add to the wealth of discussion on these subjects, and call for both potential new special issue on related subjects, as well as individual collaborations on the use of data, being big or otherwise, for social and community-driven endeavours.

As we finish such a singular year, it is time to reflect on the transition that this Journal has faced. Apart from the switch to a different format, a number of outstanding issue are still being dealt with, and we expect to solve them during the coming months. The significant delay that many contributors have faced in the review process of their articles can only be solved through an increase in participation in that process, for which I request help from the community around JoCI. We need more and more engaged reviewers.

The presentation of the Journal will continue envolving, and efforts are being done to allow for incorporating DOI numbers to future material. Indexing will also receive attention from the editorial team, which will have some changes in the coming months, to be announced during the southern summer months. Any suggestions and offers of help are welcome.

JoCI has always tried to be global journal, allowing for all different approaches and points of view to be represented. It is not a completely academic journal, in the sense that we are not bound to all the ever-more-global demands that academics are bieng subjected all around the world, both developed and emerging / developing / poor. Our only requirement / limitation is language, as English is still our world's common academic form of expression; but as a native Spanish speaker from the very specific part of the Global South called Perú, I am also open to suggestions about how to really open up the Journal to other languages. Please feel free to communicate with me about this and any other matters relevant to the collective effort that JoCI represents.

In the meantime, the world continues turning, and JoCI will continue being published. See you all on volume 13, March 2017. 